\title{
Investigations on Apoptotic Activities of Cherry Laurel Extracts in HCT-116 Human Colon Carcinoma Cells
}

\author{
Bilal Çakir ${ }^{1,2}$, İbrahim Gülseren ${ }^{3, *}$ \\ ${ }^{1}$ İstanbul Sabahattin Zaim University, Halal Foods R\&D Center, Halkalı, Küçükçekmece, İstanbul, TURKEY. \\ ${ }^{2}$ Department of Biochemistry, Marmara University, Institute of Health Sciences, Faculty of Pharmacy, Başıbüyük, Maltepe, İstanbul, \\ TURKEY. \\ ${ }^{3}$ Department of Food Engineering, İstanbul Sabahattin Zaim University, Halkalı, Küçükçekmece, İstanbul, TURKEY.
}

\begin{abstract}
Background: Cherry laurel fruits are characterized by their dark color and rich phenolic contents. Previously, phenolic extracts from cherry laurel varieties were shown to demonstrate anti-proliferative activities against cancerous cell lines. Aim: To characterize the phenolic compound content of cherry laurel varieties since their characterization is incomplete and determine their apoptotic potential. Methods: The phenolic compounds of fruit extracts from 3 different cherry laurel varieties were analyzed using an LC-MS/MS method. Using flow cytometry, apoptotic activities of cherry laurel extracts were studied against HCT-116 human colon carcinoma cells. Results: 14 different phenolic compounds were qualitatively determined, whereas for 5 compounds quantitation was possible. To the best of our knowledge, the presence of epicatechin, epigallocatechin, quercetin, quercetin-3-glucoside, procyanidin B2, delphinidine-3-O-rutinoside, delphinidine-3-Oglucoside, cyanidine-3-O-glucoside and cyanidine-3-O-rutinoside is being reported for the first time for these extracts. Although some dependence on phenolic profile and concentration was obvious, in most cases, a significant extent of apoptotic induction (40-60\%) was observed against HCT-116 cells. Conclusion: Findings on anti-proliferative and apoptotic activity verified the anti-carcinogenic capabilities of cherry laurel extracts.
\end{abstract}

Key words: Cherry laurel, Phenolic compounds, Flow cytometry, Apoptosis, LC-MS/MS analysis, Anthocyanins.

\section{INTRODUCTION}

Cancer accounts for approximately one sixth of all death events globally which sets it as the second leading cause of death immediately after circulatory system diseases. ${ }^{1}$ Around 8.9 million people lost their lives in 2016 due to oncological diseases. ${ }^{2}$ Based on these data, the potential of natural bioactive compounds demonstrating significant antioxidant and anti-carcinogenic capacity gain importance. ${ }^{3}$ Consequently, there has been an increasing extent of research interest in the utilization of bioactive components in food systems including novel functional food formulations. Especially anti-carcinogenic compounds such as polyphenolics and flavonoids, are being intensely investigated. ${ }^{4}$

The emphasis on natural compounds is in part related to the side effects of chemotherapy applications, which are still being widely practiced. In addition, due to the increasing extent of drug resistance, ${ }^{5}$ their popularity is decreasing. Furthermore, additional disadvantages of current chemotherapies may include necrotic termination of cancer cells, weight loss and malnutrition in patients. ${ }^{6}$ Consequently, natural compounds or extracts that can demonstrate anti-proliferative and apoptotic activity with no side
Submission Date: 13-12-2018; Revision Date: 06-02-2019; Accepted Date: 27-03-2019

DOI: 10.5530/ijper.53.3s.96 Correspondence: Dr. Ibrahim Gülseren, Department of Food Engineering, İstanbul Sabahattin Zaim University (iZÜ), Halkalı, Küçükçekmece- 34303, İstanbul, TURKEY. Phone: +90 2126929758 E-mail: ibrahim.gulseren@ izu.edu.tr

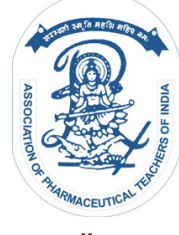

www.ijper.org 
effects and can be manufactured at high capacities and reasonable costs is highly desirable.

A number of applications combined chemotherapy along with plant extracts, which resulted in synergistic action. ${ }^{7,8}$ Phytochemicals in plant (i.e., fruit) extracts have the potential to interact synergistically, which enhances the overall anti-carcinogenic activity of an extract compared to its individual components. ${ }^{9}$ For example, a formulation which combined six anthocyanin-rich extracts from fruits exhibited elevated anti-angiogenic activity both in vitro and in vivo compared to all other combinations of these materials. ${ }^{10}$ Effective plant extracts containing bioactive phenolics that can be combined with therapy techniques or used individually in functional food formulations are highly sought after.

Cherry laurel (Laurocerasus officinalis, Roem., syn: Prunus laurocerasus L.) is a small tree or an evergreen shrub and member of Rosaceae family. In addition to being cultivated in Turkey, its areas of cultivation include the Caucasus regions, most of Balkans, Western Europe, Iran and some Mediterranean countries. ${ }^{11,12}$ Traditionally, cherry laurel was utilized for the treatment of various diseases and health problems including ulcers of the stomach, digestive and respiratory problems, hemorrhoids and eczemas and it has been utilized as a diuretic agent ${ }^{13}$ in Turkish folk medicine. Furthermore, its leaves were also shown to demonstrate certain bioactivities. ${ }^{14}$

In the previous studies, phenolic compound content of cherry laurel samples were partly identified. ${ }^{15}$ Some of the major phenolic acids found in cherry laurel were listed to include protocatechuic, p-hydroxybenzoic, chlorogenic, vanillic, caffeic, syringic and p-coumaric acids. ${ }^{15}$ In all samples, chlorogenic acid was found to be the predominant phenolic acid accounting approximately for $1020-1945 \mathrm{mg} \cdot \mathrm{kg}^{-1}$ fruit. ${ }^{15}$ Similarly gallic, protocatechuic, p-hydroxybenzoic, chlorogenic, vanillic, p-coumaric, ferulic, syringic acids, cathechin and rutin were detected in cherry laurel samples. ${ }^{16}$

When a cell dies by programmed cell death or apoptosis, this event is purely based on the activation of a certain pathway. ${ }^{17}$ Apoptosis is a critical component of many natural metabolic processes including cell turnover, functioning of the immune system, embryonic development etc., whereas any disorder in apoptotic processes could lead to the development of diseases including several cancer types. Consequently, apoptotic induction is of critical importance in the inhibition of cancer cell growth. ${ }^{18}$ Selective treatments, which lead to apoptosis of cancer cells but do not negatively affect normal cells could be utilized along with chemotherapies and potentially could enhance their efficacy. ${ }^{6}$
The ability of bioactive compounds in foods to suppress colorectal cancer growth and metastasis and induce apoptosis requires further analysis to clarify the mechanism of action. ${ }^{18}$ The regular consumption of isoflavones, anthocyanidins, flavones and flavonols is linked to reduced risk of colorectal cancer. ${ }^{19}$ In a previous study, ${ }^{20}$ the consumption of anthocyanin rich black raspberry powder lead to pronounced extents of suppression in colorectal cancers. Similarly, research on quercetin has improved its status from potentially anti-carcinogenic to an anti-cancer agent, ${ }^{21}$ since quercetin has the capacity to induce cell cycle arrest and apoptosis in cancer cells. ${ }^{22}$ In addition, quercetin was shown to increase the sensitivity of cancer cells and consequently enhance the bioavailability cancer drugs in vitro and in vivo. ${ }^{23,24}$ Considering the composition of our current extracts, chlorogenic acid was shown to induce ROS formation in colon cancer cells as well as reducing \% cellular viability. ${ }^{25}$ Catechins including EGCG (epigallocatechin-3-gallate) were shown to inhibit cancer cell proliferation while the normal cells were unaffected. ${ }^{26}$ Furthermore, ECG ${ }^{27}$ and EGCG ${ }^{28}$ were shown to demonstrate apoptotic activity against colon cancer cells. Similar observations were also reported for antiproliferative and apoptotic activities of anthocyanins, ${ }^{29}$ including delphinidin, ${ }^{30}$ cyanidin and peonidin..$^{31}$

In our previous work, three different cherry laurel extracts, whether encapsulated or free, were shown to demonstrate anti-proliferative effect against HCT116 human colon carcinoma cells, while the extent of inhibition was a function of phenolic composition and concentration of the samples. ${ }^{32}$ In this study, similar extracts were analyzed for their potential apoptotic effects. Although there is a vast literature on the influence of phenolic compounds on cancer cells, this paper represents some novel information on the influence of cherry laurel phenolics on HCT-116 cells as well as further elucidating the phenolic constituents of cherry laurel varieties.

\section{MATERIALS AND METHODS}

\section{Materials}

All chemicals were purchased from Sigma-Aldrich Corp (St. Louis, MO, USA) and used without further purification.

\section{Extraction of Cherry Laurel Phenolics}

The fruit samples utilized in the current study were supplied by the TAGEM Black Sea Agricultural Research Institute Directorate, Samsun, Turkey and accounted for three different cherry laurel varieties $(55 \mathrm{~K} 06,61 \mathrm{~K} 04$ and 61K05). TAGEM (General Directorate of Agri- 
cultural Research and Policies) is an official branch of Turkish Ministry of Agriculture and Forestry. The characterization of cherry laurel specimens were previously carried out by TAGEM and their records are listed on TAGEM databases. Since the samples were supplied directly by TAGEM, the acquisition method is highly reproducible. All samples were grown in Samsun and Trabzon and picked upon full ripeness and stored by the Directorate $\left(-20^{\circ} \mathrm{C}\right)$ until the samples were requested. 55K06 was picked in Samsun approx. 30m above the sea level. 61K04 and 61 K05 were harvested in Trabzon, near Arakli Yalıboyu. The corresponding heights were 10 and $40 \mathrm{~m}$, respectively. For the extraction of phenolic compounds, $40 \mathrm{~g}$ fresh fruit was combined with $400 \mathrm{ml}$ methanol and the mixture was kept sonicated in a $65^{\circ} \mathrm{C}$ water bath for $15 \mathrm{~min} . .^{33}$ Insoluble materials were removed via filtration through syringe filters $(0.45$ $\mu \mathrm{m})$. In order to remove methanol from the extracted phenolics, rotary evaporation was utilized $\left(40^{\circ} \mathrm{C}\right)$. Consequently, extracted compounds were successfully concentrated and the extracts of all three varieties were refrigerated until further usage.

\section{LC-MS/MS Analysis of Cherry Laurel Extracts}

The LC system consisted of a Nexera XR UFLC (SHIMADZU, Kyoto, Japan). Chromatographic separation of cherry laurel extracts was performed on the Raptor Biphenyl column $(100 \times 2.3 \mathrm{~mm}$ i.d., $2.7 \mu \mathrm{m}$, Restek, Bellefonte, PA, USA). The binary mobile phase consisted of mobile phase A: water: acetic acid $(1000: 1, v / v)$ and mobile phase B: methanol: acetic acid (1000:1, $v / v)$. The flow rate was $0.5 \mathrm{~mL} / \mathrm{min}^{-1}$ and the column temperature was $40^{\circ} \mathrm{C}$. The multiple step gradient program was as follows: $0-5 \mathrm{~min}, 5 \% \mathrm{~B}$; $5-10 \mathrm{~min}, 5-90 \% \mathrm{~B} ; 10-18$ min, down to $80 \% \mathrm{~B} ; 18-30 \mathrm{~min}$, down to $5 \% \mathrm{~B}$. The overall run time was $30 \mathrm{~min}$. The $\mathrm{LC}$ system was interfaced with an LCMS-8045 Triple Quadrupole System (Shimadzu, Kyoto, Japan). Negative ionization electrospray mass spectrometry was operated in the Selected Reaction Monitoring (SRM) scan mode. For the analysis of cherry laurel extracts, the optimal instrumental conditions were as follows: ion spray voltage was $-4500 \mathrm{~V}$, capillary temperature was $250^{\circ} \mathrm{C}$. Nitrogen was used as both the nebulizing and drying gas at a rate of 3 and 12 min. $\mathrm{L}^{-1}$, respectively. All data obtained were optimized by matching the analytical standards from SigmaAldrich. The used products and their corresponding numbers can be listed as follows: Epicatechin (68097), epigallocatechin (8108), rutin (R5143), delphinidin-3-Oglucoside (73705) and cyaniding-3-O-glucoside (44689).

\section{Cell Culture}

Cell culture investigations were carried out at GEMHAM, Marmara University, İstanbul, Turkey. Human
Colon Carcinoma Cells (HCT-116) were cultured on McCoy's medium containing 10\% FBS and 1\% L-glutamine. Number of viable cells were quantified by trypan blue. Inoculation was applied to petri dishes $(60 \mathrm{~mm})$ where the concentration of HCT-116 cells was $3 \times 10^{6}$. Upon incubation at $37^{\circ} \mathrm{C}$ and on an incubator atmosphere containing $5 \% \mathrm{CO}_{2}$, cellular adhesion took place.

\section{Evaluation of Apoptosis by Flow Cytometry}

Apoptotic potential of the cherry laurel extracts was evaluated using flow cytometry. Seed cells $\left(1 \times 10^{6}\right.$ cells) were cultivated in a T25 culture flask in triplicate experiments along with the control flasks containing the unstained, only Annexin V stained or only Propidium Iodide (PI) stained cells. The total volume was $500 \mu$, which consisted of $400 \mu$ l of cells and $100 \mu$ lof incubation buffer which was free of stains or contained either Annexin V or PI $(2 \mu \mathrm{l}$, at a concentration of $1 \mathrm{mg} /$ $\left.\mathrm{ml}^{-1}\right)$. After $24 \mathrm{hr}$ incubation under appropriate conditions $\left(37^{\circ} \mathrm{C}, 5 \% \mathrm{CO}_{2}\right)$, cherry laurel extracts were administered at varying concentrations. Following a $24 \mathrm{hr}$ incubation with the treatments, the adherent cells were trypsinized in each T25 flask. The collected cells were washed with Phosphate Buffered Saline (PBS) twice and centrifuged (670xg, $5 \mathrm{~min}$ ) immediately afterwards. The precipitated cells were resuspended once again in PBS and prepared for flow cytometry experiments in appropriate tubes. The tubes contained $400 \mu \mathrm{L}$ cellular suspension, $10 \mu \mathrm{L}$ incubation buffer, $2 \mu \mathrm{L}$ Annexin- $\mathrm{V}$ and $2 \mu \mathrm{L}$ PI. The tubes were analyzed using a flow cytometry instrument (BD FACS Calibur 4CS Flow Cytometer, BD Biosciences, San Jose, CA, USA). Cells that were negative for both PI and Annexin- $V$ negative were considered healthy. PI negative and Annexin positive cells were considered apoptotic, whereas cells that were positive to both stains were considered late apoptotic or necrotic since these staining methods do not differentiate between late apopototic or necrotic cells. ${ }^{34-37}$

\section{Statistical Analysis}

Data generated in this study were shown and plotted as the sample mean \pm its corresponding standard deviation obtained from at least triplicate experiments. For cell culture experiments, at least 6 replicate experiments were carried out. Statistical significance of the treatments was also tested using ANOVA tests $(p<0.0001)$. When necessary, SPSS 25.0 software was utilized to ensure statistical validity.

\section{RESULTS AND DISCUSSION}

\section{Chemical Analysis of Plant Extracts}

First of all, phenolic extracts were prepared as described above and in Çakır and Gülseren (2017) ${ }^{32}$ and their 
compositions were determined based on an LC-MS/MS technique. Consequently, phenolic compounds present in the extracts were analyzed by mass detection (Table 1). The structure of the compounds identified in the current extracts were listed on Figure 1. In these analyses, MS and MS/MS signals were detected and it was possible to identify 14 compounds based on their fragmentation characteristics. However, due to the absence of appropriate standards, for only 5 of them, quantification was possible (Table 1).

Among these 5 compounds, compound 1 showed a molecular ion at $\mathrm{m} / \mathrm{z} 465$ corresponding to the molecular formula $\mathrm{C}_{21} \mathrm{H}_{22} \mathrm{O}_{12}$ and in MS/MS gave one principal product ion at $\mathrm{m} / \mathrm{z}$ 301, which corresponds to the loss of a glucose moiety. In comparison to the reference, this compound was identified as delphinidin-3-O-glucoside. Compound 2 showed a molecular ion at $\mathrm{m} / \mathrm{z} 449$ corresponding to the molecular formula $\mathrm{C}_{21} \mathrm{H}_{22} \mathrm{O}_{11}$ while after fragmentation, one principal product ion formed at $\mathrm{m} / \mathrm{z} 287$, which corresponds to the loss of a glucose moiety. In this case, the compound was identified as cyanidin-3-O-glucoside. Compound 3 showed a molecular ion at $\mathrm{m} / \mathrm{z} 609$ corresponding to the molecular formula $\mathrm{C}_{27} \mathrm{H}_{30} \mathrm{O}_{16}$. In MS/MS, two principal product ions formed at m/z 299.9 and 270.95, which corresponds to the loss of a rutinose moiety. Consequently, this compound was identified as rutin. Compound 4 showed a molecular ion at $\mathrm{m} / \mathrm{z} 289$ corresponding to the molecular formula $\mathrm{C}_{15} \mathrm{H}_{14} \mathrm{O}_{6}$. Its corresponding principal product ions were observed at m/z 122.8 and 109. Consequently, this compound was identified as epicatechin. Finally, compound 5 showed a molecular ion at $\mathrm{m} / \mathrm{z}$ 305. Its molecular formula corresponded to $\mathrm{C}_{15} \mathrm{H}_{14} \mathrm{O}_{7}$. In MS/MS analysis, two principal product ions formed at $\mathrm{m} / \mathrm{z} 122.8$ and 109 . The compound was identified as epigallocatechin.

The concentration of these 5 compounds largely varied between the 3 varieties of cherry laurel investigated in this study. Among the compounds quantified here Cyanidine-3-O-glucoside (C3G) was notably high in concentration in all samples, while $61 \mathrm{~K} 04$ was the richest source. Delphinidine-3-O-glucoside (D3G) was the second most abundant source of anthocyanins in these 3 extracts, which was especially high in $61 \mathrm{~K} 04$ and $61 \mathrm{~K} 05$ varieties. To the best of our knowledge, the presence of epicatechin, Epigallocatechin (EGC), quercetin, quercetin-3-glucoside, procyanidin B2, D3G, delphinidine-3-O-rutinoside, C3G and cyanidine-3-Orutinoside in cherry laurel extracts is reported here for the first time. One specific example on LC-MS/ MS profiles of the samples are given on Figure 2 for Epigallocatechin (EGC). Figure 2A demonstrates the chromatographic separation peak for EGC in all three cases, for which the quantitative data are presented on Table 1. On Figure 2B, fragmentation characteristics is shown for EGC. As previously investigated, current extracts demonstrated considerable Gallic Acid Equivalency (GAE) values around $4000 \mathrm{mg} / \mathrm{kg}^{-1} \cdot{ }^{32}$ Considering these findings and the anti-proliferative potential of the extracts, current samples were analyzed for their potential apoptotic activities.

\section{Induction of Apoptosis by Cherry Laurel Extracts}

In our previous studies, the anti-proliferative activity of cherry laurel extracts was demonstrated against HCT-116 human colon carcinoma cells. Under simulated gastrointestinal media, their dissolution kinetics and efficacy in cell culture were determined. The fractions dissolved in simulated gastrointestinal media were shown to inhibit HCT-116 cells by approx. $85 \%$, even after $20 \mathrm{x}$ dilution in most cases. ${ }^{32}$

In the current study, the extent of apoptotic induction was studied by flow cytometry. In this assay, the cellular staining of cells is regarded as a measure of the apoptotic state or lack of it. For example, cells that were

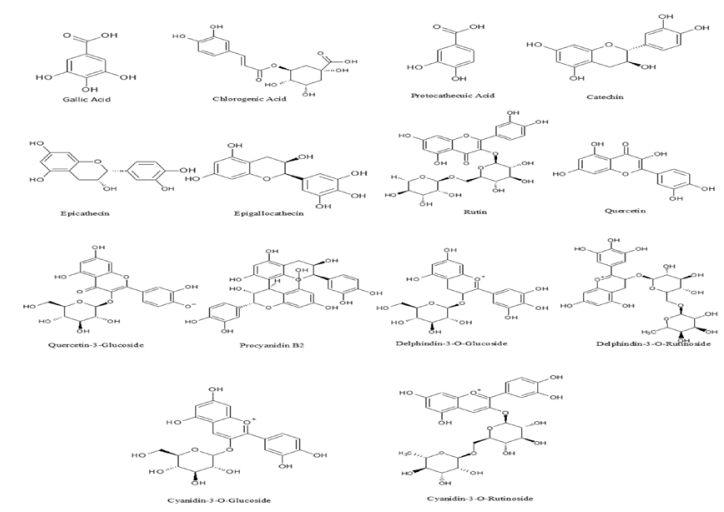

Figure 1: Structures of Phenolic Molecules Identified in the Cherry Laurel Extracts.

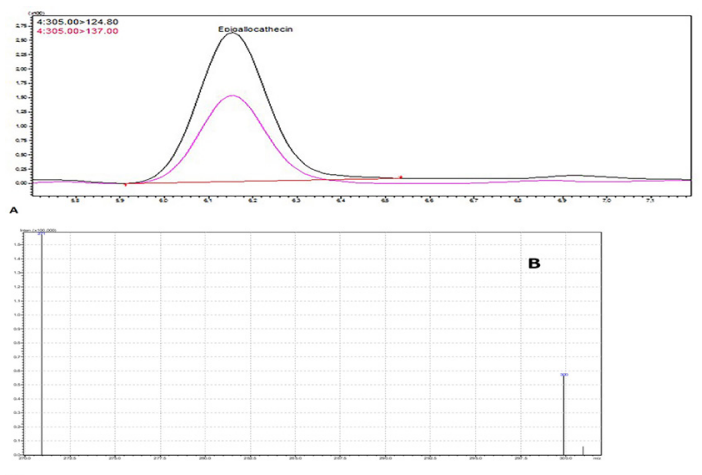

Figure 2: Determination of Phenolic Compounds in Cherry Laurel Extracts by LC-MS/MS. A. Chromatographic separation of epigallocatechin. B. Mass spectrometric determination of the ionization characteristics of epigallocatechin. 


\begin{tabular}{|c|c|c|c|c|c|}
\hline \multirow{2}{*}{ Compound identity } & \multirow{2}{*}{$\begin{array}{c}M- \\
H-(m / z)\end{array}$} & \multirow{2}{*}{$\mathrm{MS}^{2}(\mathrm{~m} / \mathrm{z})$} & \multicolumn{3}{|c|}{ Concentration, mg. $\mathbf{k g}^{-1}$ extract weight $(n=3)$} \\
\hline & & & $55 \mathrm{~K} 06$ & $61 \mathrm{~K} 04$ & $61 \mathrm{~K} 05$ \\
\hline Gallic acid & 168.8 & $124.8,79$ & ND & ND & ND \\
\hline Chlorogenic acid & 353 & 191,179 & ND & ND & ND \\
\hline Protocatechuic acid & 153 & 109 & ND & ND & ND \\
\hline Catechin & 289 & 123.1, 109 & ND & ND & ND \\
\hline Epicatechin & 289 & $122.8,109$ & $154.93 \pm 10.9$ & $25.88 \pm 1.8$ & $60.49 \pm 4.2$ \\
\hline Epigallocatechin & 305 & $137,124.8$ & $69.55 \pm 5.6$ & $197.13 \pm 15.8$ & $293.25 \pm 23.5$ \\
\hline Rutin & 609 & $299.9,270.95$ & $2.85 \pm 0.1$ & $0.89 \pm 0.04$ & $0.12 \pm 0.01$ \\
\hline Quercetin & 301 & 171,159 & ND & ND & ND \\
\hline Quercetin-3-glucoside & 464 & 301 & ND & ND & ND \\
\hline Procyanidin B2 & 579 & 460 & ND & ND & ND \\
\hline Delphinidin-3-O-glucoside & 465 & 301 & $50.23 \pm 5$ & $228.94 \pm 22.9$ & $135.49 \pm 13.6$ \\
\hline Delphinidin-3-O-rutinoside & 609 & 463,301 & ND & ND & ND \\
\hline Cyanidin-3-O-glucoside & 449 & 287 & $122.19 \pm 7.3$ & $622.43 \pm 37.4$ & $422.56 \pm 25.4$ \\
\hline Cyanidin-3-O-rutinoside & 593 & 447,285 & ND & ND & ND \\
\hline
\end{tabular}

negative for both PI and Annexin- $\mathrm{V}$ were regarded as healthy cells. Annexin-V positive cells were considered as apoptotic (i.e., early apoptotic) and the cells that were stained by both molecules were regarded as late apoptotic or necrotic. The flow cytometry data is summarized on Figure 3A-C for all concentrations of the three extracts. In all cases, control samples contained a low concentration of apoptotic cells $(<5 \%)$, while lower left quadrant represented much larger extent of viable cells in all cases. As increasing amounts of cherry laurel extracts were administered, induction of apoptosis took place. Increasingly more cells become Annexin$\mathrm{V}$ positive (lower right quadrant) or positive for both stains (upper right quadrant). With the exception of the $2 \%$ treatment for 55K06 (Figure 3C), the trends clearly indicated apoptotic activity. To summarize the findings, cherry laurel extracts significantly increased $\%$ apoptotic cells compared to the controls (Figure 3).

The extent of total apoptotic cells in the samples was plotted as a function of cherry laurel extract concentration (Figure 4). Among the three extracts, 61K04 treatments induced the formation of largest number $\%$ of apoptotic cells (Approx. 63\%) at an extract concentration of $4 \%$ (Figure $4 \mathrm{~A}$ ). In general, for all extracts, the overall trend was larger extent of apoptotic induction with increasing extract concentrations. However, beyond a certain concentration (4-6\%), the number of apoptotic cells did not seem to increase for $61 \mathrm{~K} 04$ or
55K06 treated cells. These findings might be in part due to experimental limitations or the fact that a relatively high concentration of cells went through late apoptosis or necrosis, which might have further complicated the measurements. In any case, the extracts induced at least 40 to $60 \%$ of the cancer cells to go through apoptosis and/or necrosis. Compared to the controls, $\%$ apoptotic or necrotic cells considerably increased by 0.86 to 14.9 times based on the extract composition and concentration. These findings indicated considerably high apoptotic activity both in terms of the increase in apoptotic activity compared to the controls ${ }^{7}$ and also the $\%$ concentration of cells that underwent apoptosis. ${ }^{38}$

In Figure 5, the extent of cells which become late apoptotic or necrotic were demonstrated. At relatively low concentrations (mostly 2-6\% extract), the extent of late apoptotic or necrotic cells appeared to be a function of phenolic composition of the extract. As extract concentrations increased, especially to $10 \%$, the majority of the apoptotic cells (approx. 90-100\%) could be considered as dead cells. At these higher concentrations, the influence of the phenolic profile was much less significant. Based on our earlier studies, $61 \mathrm{~K} 04$ extract was the most potent growth inhibitor for HCT-116 cells at a phenolic concentration corresponding to $3738 \mathrm{mg}$ GAE per $\mathrm{kg}$ extract. ${ }^{32}$ As shown on Table 1 , this extract also had the highest concentration of anthocyanins quantified here and consequently anthocyanin content (i.e., D3G and 

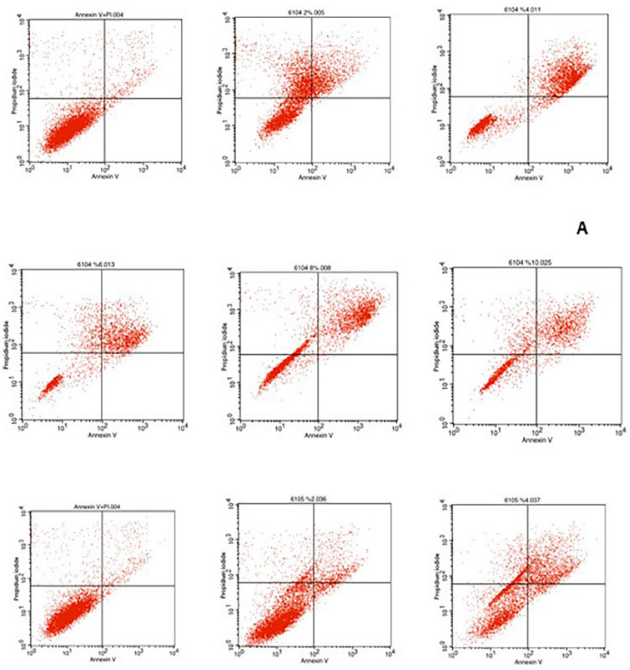

B
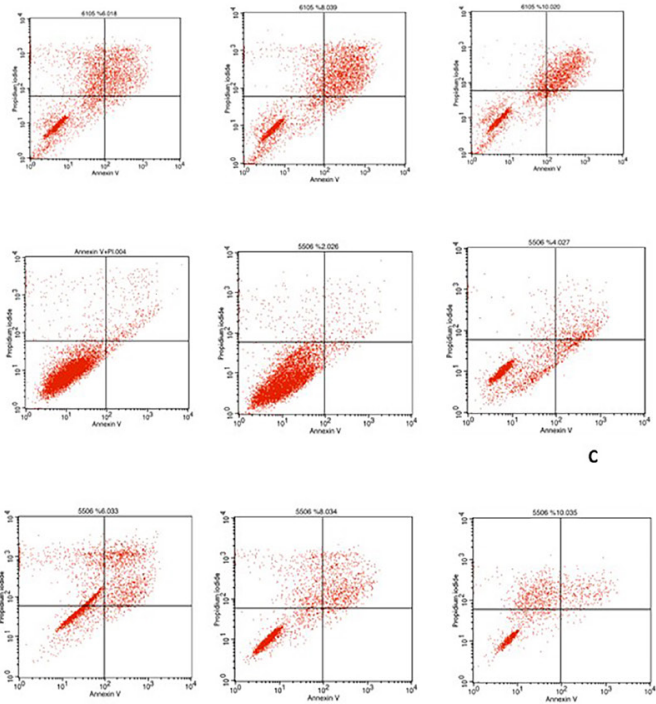

Figure 3: Flow Cytometry Analysis of Apoptosis in HCT-116 Cells After $24 \mathrm{hr}$ Incubation with three different cherry laurel extracts at an extract concentration of $0,2,4,6,8$ and $10 \%$ for A. $61 \mathrm{~K} 04$ extract, B. $61 \mathrm{~K} 05$ extract and C. 55K06 extract. Every sub-figure indicates these 6 concentrations $0 \%$ being represented at the top left and $10 \%$ at the bottom right. Concentration increases first to the right, then to the bottom.

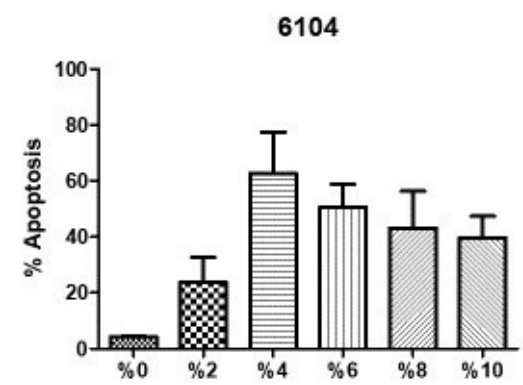

Figure 4A

6105

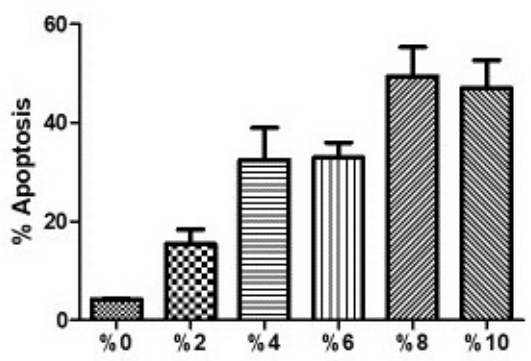

Figure 4B

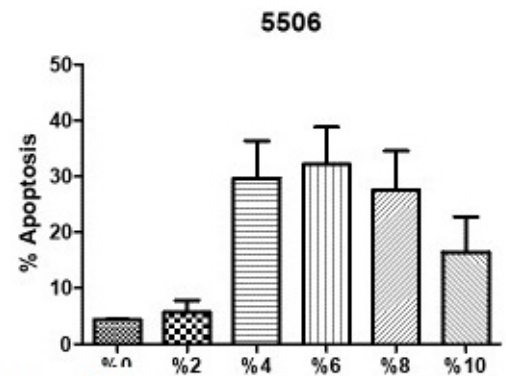

Figure 4C

Figure 4: \% Apoptotic HCT-116 Cells as a Function of Cherry Laurel Extract Concentration ( $0 \%, 2 \%, 4 \%, 6 \%, 8 \%$ and $10 \%)$ and extract type (A. $61 \mathrm{~K} 04$, B. $61 \mathrm{~K} 05$ and C. $55 \mathrm{~K} 06$ extracts). Compared to the control group, all values for apoptotic cells in all treatments were significantly higher with the exception of the $2 \%$ treatment for $55 \mathrm{~K} 06$ based on 1-way ANOVA-repeated measures analysis at a level of $p<0.0001$.

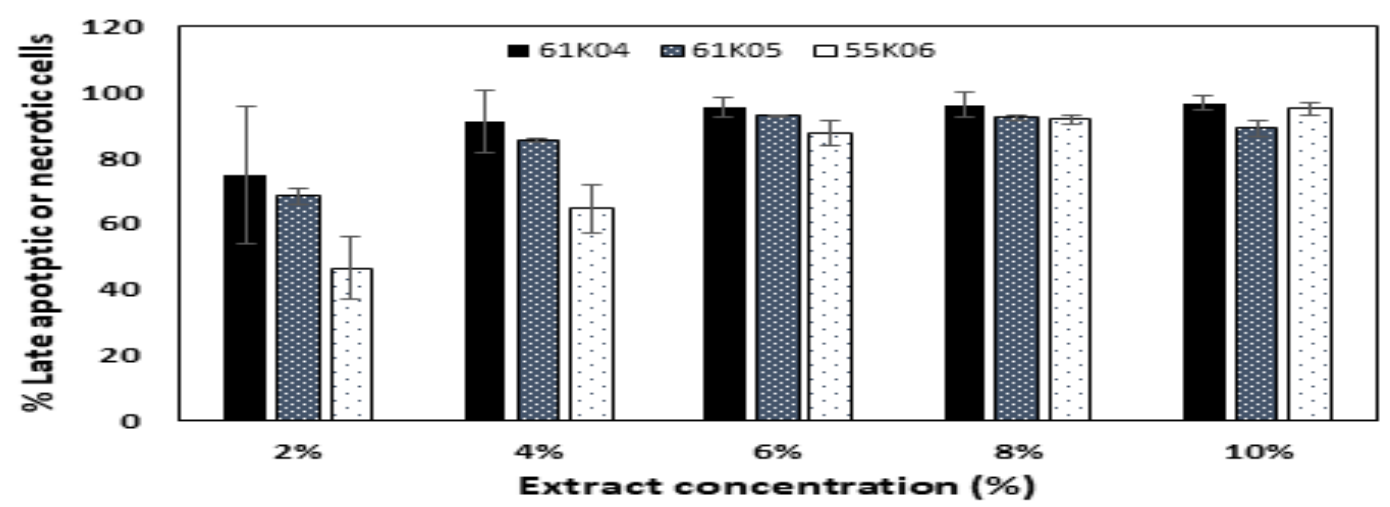

Figure 5: \% Late Apoptotic or Necrotic HCT-116 Cells as a Function of Cherry Laurel Extract Concentration (0\%, 2\%, 4\%, 6\%, 8\% and 10\%) and Extract Type (61K04, $61 \mathrm{~K} 05$ and $55 \mathrm{~K} 06$ extracts). 
Table 2: IC $\mathbf{C}_{50}$ values of the Cherry Laurel Extracts. Since extracts were used instead of purified phenolics, $I_{50}$ values were calculated based on the Gallic Acid Equivalency (GAE) values of the extracts.

\begin{tabular}{|c|c|}
\hline Extract Name & IC $_{50}$ (mg GAE phenolics. L $^{-1}$ ) \\
\hline $61 \mathrm{~K} 04$ & 2.68 \\
\hline $61 \mathrm{~K} 05$ & 3.55 \\
\hline $55 \mathrm{~K} 06$ & 7.15 \\
\hline
\end{tabular}

C3G) might partly be related to its anti-proliferative and apoptotic effects. In the previous studies, for example, D3G was shown to be an effective agent for the inhibition of HCT-116 cells. ${ }^{39}$ Delphinidin was also found to be more efficient than cyanidine, malvidin and pelargonidin in the inhibition of metastatic colon cancer cells. ${ }^{40}$ Consequently, phenolic profiles of the extracts can be anticipated to have a strong bearing on the anti-proliferative and apoptotic activities of the extracts. In the current set of experiments, $50 \%$ inhibitory concentrations $\left(\mathrm{IC}_{50}\right)$ of the extracts were determined based on their Gallic Acid Equivalency (GAE) values (Table 2). Since both the phenolic constituents and their corresponding concentration in the extracts largely vary, the calculation of $\mathrm{IC}_{50}$ was based on GAE values. $61 \mathrm{~K} 04$ extracts were found to be the most effective extract due to the low $\mathrm{IC}_{50}$ value. This finding can be in part be attributed to the relatively higher concentration of anthocyanins in $61 \mathrm{~K} 04$ extracts.

\section{CONCLUSION}

In our previous studies, the anti-proliferative activity of cherry laurel extracts was demonstrated against HCT-116 cells. Under simulated gastrointestinal media, their dissolution kinetics and efficacy in cell culture were determined for both encapsulated and free extracts. In the current study, using flow cytometry, the capabilities of cherry laurel extracts to induce apoptosis were investigated. Although some dependence on phenolic profile and extract concentration was obvious and potentially anthocyanins played an important role, in most cases, a significant extent of apoptotic induction was observed for HCT-116 human colon carcinoma cells. These findings were coherent with our earlier findings on the anti-proliferative capabilities of cherry laurel extracts. Especially at relatively high extract concentrations, the majority of cells were late apoptotic or necrotic. In conclusion, both sets of findings verified the anti-carcinogenic capabilities of cherry laurel extracts. The mechanism responsible for the induction of apoptosis in HCT-116 cells remains to be studied. Future work on combining various cell lines in order to further demonstrate activity and safety of the extracts and establishment of combinatorial therapies are currently being planned.

\section{ACKNOWLEDGEMENT}

The current study work was funded by a grant from TAGEM R\&D Support Programme, Turkey [grant number: TAGEM-14/AR-GE/27]. We would like to thank Dr. İdris Macit from the Black Sea Agricultural Research Institute of TAGEM, for providing the fruit samples. The authors are grateful to Assoc. Prof. Betül Karademir and Dr. Ayşe Mine Yllmaz for their support during cell culture studies. Finally, we would like to thank Mr. Murat Onul, Ant Teknik, Turkey, for his support in LC-MS/MS analysis.

\section{CONFLICT OF INTEREST}

The authors declare no conflict of interest.

\section{ABBREVIATIONS}

LC-MS/MS: Liquid Chromatography Tandem-Mass Spectrometry; PI: Propidium Iodide; PBS: Phosphate buffered saline; ANOVA: Analysis of Variance; GAE: Gallic Acid Equivalency.

\section{REFERENCES}

1. Naghavi M, Abajobir AA, Abbafati C, Abbas KM, Abd-Allah F, et al. Global, regional and national age-sex specific mortality for 264 causes of death, 1980-2016: A systematic analysis for the Global Burden of Disease Study 2016. The Lancet. 2017;390(10100):1151-210.

2. Anonymous. IHME Global Burden of Disease (GBD). 2018. http://ghdx. healthdata.org/gbd-results-tool.

3. Gil-Chávez GJ, Villa JA, Ayala-Zavala FJ, Heredia JB, Sepulveda D, Yahia EM, et al. Technologies for extraction and production of bioactive compounds to be used as nutraceuticals and food ingredients: An overview. Compr Rev Food Sci Food Saf. 2013;12(1):5-23.

4. Ferrazzano GF, Amato I, Ingenito A, Zarrelli A, Pinto G, Pollio A. Plant polyphenols and their anti-cariogenic properties: A review. Molecules. 2011;16(2):1486-507.

5. Morré DM, Morré DJ. Anticancer activity of grape and grape skin extracts alone and combined with green tea infusions. Cancer Lett. 2006;238(2):2029.

6. Sak K. Chemotherapy and dietary phytochemical agents. Chemother Res Prac. 2012;2012. Article ID 282570.

7. Majumdar AP, Banerjee S, Nautiyal J, Patel BB, Patel V, Du J, et al. Curcumin synergizes with resveratrol to inhibit colon cancer. Nutr Cancer. 2009;61(4):544-53.

8. Seeram NP, Adams LS, Henning SM, Niu Y, Zhang Y, Nair MG, et al. In vitro antiproliferative, apoptotic and antioxidant activities of punicalagin, ellagic acid and a total pomegranate tannin extract are enhanced in combination with other polyphenols as found in pomegranate juice. J Nutr Biochem. 2005;16(6):360-7.

9. DeKok TM, Breda SGV, Manson MM. Mechanisms of combined action of different chemopreventive dietary compounds: A review. Eur J Nutr. 2008;47(Suppl 2):51-9.

10. Bagchi D, Sen CK, Bagchi M, Atalay M. Anti-angiogenic, antioxidant and anticarcinogenic properties of a novel anthocyanin-rich berry extract formula. Biochem. 2004;69(1):75-80. 
11. Kolayli S, Küçük M, Duran C, Candan F, Dincer B. Chemical and antioxidant properties of Laurocerasus officinalis Roem. (cherry laurel) fruit grown in the Black Sea region. J Agric Food Chem. 2003;51(25):7489-94.

12. Sahan Y, Cansev A, Celik G, Cinar A. Determination of various chemical properties, total phenolic contents, antioxidant capacity and organic acids in Laurocerasus officinalis fruits. Acta Hort. 2012;939(939):359-66.

13. Halilova H, Ercisli S. Several physico-chemical characteristics of cherry laurel (Laurocerasus officinalis Roem.) fruits. Biotechnol Biotech Equip. 2010;24(3):1970-3.

14. Yesilada E, Sezik E, Honda G, Takaishi Y, Takeda Y, Tanaka T. Traditional medicine in Turkey IX: Folk medicine in north-westAnatolia. J Ethnopharmacol. 1999;64(3):195-210.

15. Alasalvar C, Al-Farsi M, Shahidi F. Compositional characteristics and antioxidant components of cherry laurel varieties and pekmez. J Food Sci. 2005;70(1):47-52.

16. Karahalil FY, Şahin H. Phenolic composition and antioxidant capacity of Cherry laurel (Laurocerasus officinalis Roem.) sampled from Trabzon region, Turkey. Afr J Biotechnol. 2011;10(72):16293-9.

17. Vaux DL, Hacker G, Strasser A. An evolutionary perspective on apoptosis. Cell. 1994;76(5):777-9.

18. Falkenhorst J, Grunewald $\mathrm{S}$, Mühlenberg $\mathrm{T}$, Marino-Enriquez A, Reis AC, Corless C, et al. Inhibitor of Apoptosis Proteins (IAPs) are commonly dysregulated in GIST and can be pharmacologically targeted to enhance the pro-apoptotic activity of imatinib. Oncotarget. 2016;7(27):41390-403.

19. Rossi M, Negri E, Talamini R, Bosetti C, Parpinel M, Gnagnarella P, et al. Flavonoids and colorectal cancer in Italy. Cancer Epidemiol Biomarkers Prev. 2006;15(8):1555-8.

20. Wang LS, Arnold M, Huang YW, Sardo C, Seguin C, Martin E, et al. Modulation of genetic and epigenetic biomarkers of colorectal cancer in humans by black raspberries: A phase I pilot study. Clin Cancer Res. 2011;17(3):598-610.

21. Altundag EM, Kasaci T, Yilmaz AM, Karademir B, Kocturk S, Taga Y, et al. Quercetin-induced cell death in human papillary thyroid cancer (B-CPAP) cells. J Thyroid Res. 2016. Article ID 9843675.

22. Choi JA, Kim JY, Lee JY, Kang CM, Kwon HJ, Yoo YD, et al. Induction of cell cycle arrest and apoptosis in human breast cancer cells by quercetin. Int $\mathrm{J}$ Oncol. 2001;19(4):837-44.

23. Gibellini L, Pinti M, Nasi M, Montagna JP, DeBiasi S, Roat E, et al. Quercetin and cancer chemoprevention. J Evid Based Complement Alternat Med. 2011;2011:591356.

24. Fantini M, Benvenuto M, Masuelli L, Frajese GV, Tresoldi I, Mpdesti A, et al. In vitro and in vivo antitumoral effects of combinations of polyphenols or polyphenols and anticancer drugs: Perspectives on cancer treatment. Int J Mol Sci. 2015;16(5):9236-82.

25. Hou N, Liu N, Han J, Yan Y, Li J. Chlorogenic acid induces reactive oxygen species generation and inhibits the viability of human colon cancer cells. AntiCancer Drugs. 2017;28(1):59-65.

26. Chen ZP, Schell JB, Ho CT, Chen KY. Green tea epigallocatechin gallate shows a pronounced growth inhibitory effect on cancerous cells but not on their normal counterparts. Cancer Lett. 1998;129(2):173-9.
27. Baek SJ, Kim JS, Jackson FR, Eling TE, McEntee MF, Lee SH. Epicatechin gallate-induced expression of NAG-1 is associated with growth inhibition and apoptosis in colon cancer cells. Carcinog. 2004;25(12):2425-32.

28. Park IJ, Lee YK, Hwang JT, Kwon DY, Ha J, Park OJ. Green tea catechin controls apoptosis in colon cancer cells by attenuation of $\mathrm{H} 2 \mathrm{O} 2$ - stimulated COX-2 expression via the AMPK signaling pathway at low-dose $\mathrm{H} 2 \mathrm{O} 2$. Ann N Y Acad Sci. 2009;1171(1):538-44.

29. Wang LS, Stoner GD. Anthocyanins and their role in cancer prevention. Cancer Lett. 2008;269(2):281-90.

30. Yun JM, Afaq F, Khan N, Mukhtar H. Delphinidin, an anthocyanidin in pigmented fruits and vegetables, induces apoptosis and cell cycle arrest in human colon cancer HCT116 cells. Mol Carcinog. 2009;48(3):260-70.

31. Chen PN, Chu SC, Chiou HL, Chiang CL, Yang SF, Hsieh YS. Cyanidin 3-glucoside and peonidin 3-glucoside inhibit tumor cell growth and induce apoptosis in vitro and suppress tumor growth in vivo. Nutr Cancer. 2005;53(2):232-43.

32. Çakır B, Gülseren I. Dissolution kinetics of polyphenol bearing calcium pectate hydrogels in simulated gastric or intestinal media and their anti-carcinogenic capacities. Food Hydrocoll. 2017;70:69-75.

33. Karabegovic IT, Stojičević SS, Veličković DT, Todorovic ZB, Nikolić NC, Lazić ML. The effect of different extraction techniques on the composition and antioxidant activity of cherry laurel (Prunus laurocerasus) leaf and fruit extracts. Ind Crop Product. 2014;54:142-8.

34. Fadok VA, Voelker DR, Campbell PA, Cohen JJ, Bratton DL, Henson PM. Exposure of phosphatidylserine on the surface of apoptotic lymphocytes triggers specific recognition and removal by macrophages. J Immunol. 1992;148(7):2207-16.

35. Frey T. Correlated flow cytometric analysis of terminal events in apoptosis reveals the absence of some changes in some model systems. Cytometry. 1997;28(3):253-63.

36. Darzynkiewicz Z, Bruno S, DelBino G, Gorczyca W, Hotz MA, Lassota P, et al. Features of apoptotic cells measured by flow cytometry. Cytometry. 1992;13(8):795-808.

37. Darzynkiewicz Z, Juan G, Li X, Gorczyca W, Murakami T, Traganos F. Cytometry in cell necrobiology: analysis of apoptosis and accidental cell death (necrosis). Cytometry. 1997;27(1):1-20.

38. Plastina P, Bonofiglio D, Vizza D, Fazio A, Rovito D, et al. Identification of bioactive constituents of Ziziphus jujube fruit extracts exerting antiproliferative and apoptotic effects in human breast cancer cells. J Ethnopharmacol. 2012;140(2):325-32.

39. Shin DY, Lu JN, Kim GY, Jung JM, Kang HS, Lee WS, et al. Antiinvasive activities of anthocyanins through modulation of tight junctions and suppression of matrix metalloproteinase activities in HCT-116 human colon carcinoma cells. Oncology Reports. 2011;25(2):567-72.

40. Cvorovic J, Tramer F, Granzotto M, Candussio L, Decorti G, Passamonti S. Oxidative stress-based cytotoxicity of delphinidin and cyanidin in colon cancer cells. Arch Biochem Biophys. 2010;501(1):151-7.

\section{SUMMARY}

- Phenolic compound content of cherry laurel varieties were investigated and their apoptotic potential was determined.

- The phenolic compounds of fruit extracts from 3 different cherry laurel varieties were analyzed using an LC-MS/MS method.

- Using flow cytometry, apoptotic activities of cherry laurel extracts were studied against HCT116 human colon carcinoma cells.

- Although some dependence on phenolic profile and concentration was obvious, mostly, a significant extent of apoptotic induction (40-60\%) was observed against HCT-116 cells. 


\section{PICTORIAL ABSTRACT}
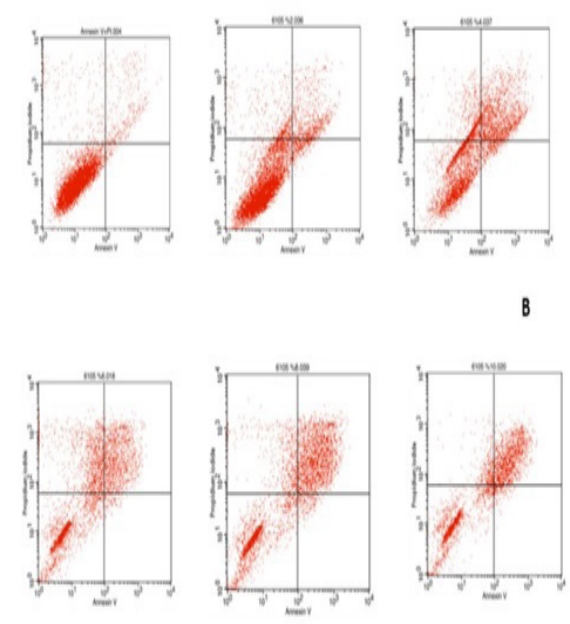

B

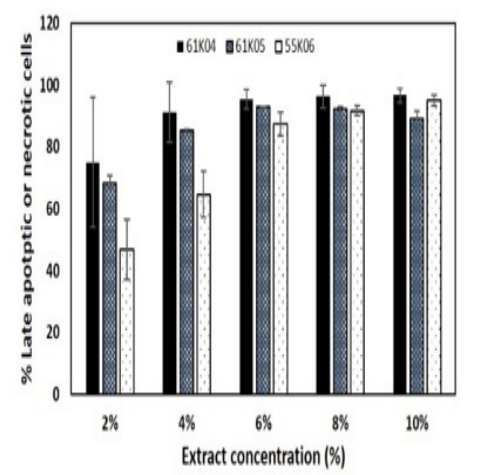

Cherry laurel phenolics induce apoptosis in HCT-116 human colon carcinoma cells and lead $40-60 \%$ of them to late apoptosis or necrosis.

\section{ABOUT AUTHORS}

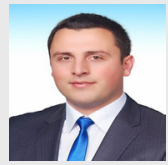

Mr. Çakır completed his BS education in Chemistry (2008) and served at various analytical and academic labs in the Analysis of Foods, Cosmetics and Pharmaceuticals. He has served in various national and international projects as a team member. He has published 6 peer-reviewed papers over the last 3 years in scientific journals. He is currently an MS student in Biochemistry (Marmara University, Turkey).

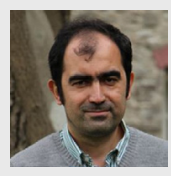

Dr. Gülseren completed his education in various universities in Turkey, USA and Canada (İTÜ, University of Tennessee, Penn State, University of Guelph, IZZ̈̈). He has published approximately 30 international publications and presented more than 20 presentations in various conferences. He is serving as a faculty member at İZ̈̈, Department of Food Engineering since 2013.

Cite this article: Çakir B, Gülseren I. Investigations on Apoptotic Activities of Cherry Laurel Extracts in HCT-116 Human Colon Carcinoma Cells. Indian J of Pharmaceutical Education and Research. 2019;53(3 Suppl 2):s264-s272. 